\title{
A ORALIDADE DA LINGUAGEM FRENTE À CULTURA ESCRITA
}

Denize Elena Garcia da Silva*

\begin{abstract}
RESUMO: O artigo discute a oralidade da linguagem, destacando algumas das questões mais relevantes para o estudo do tema, principalmente quando abordado em relação à língua escrita. Parte-se das concepçōes sobre a oralidade para enfocá-la dentro de uma equação possível num paralelo com a escrita. Na busca da trajetória da oralidade, traça-se um percurso desde a fórmula de Homero aos valores sociais da fala e da escrita, associados ao letramento.
\end{abstract}

PALAVRAS-CHAVE: oralidade; lingua escrita; valores sociais; letramento.

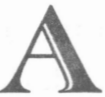

oralidade é, em principio, um processo natural de comunicação lingüística que antecede ao processo de educação formal direcionado à lectoescritura ou ao letramento. Por um lado, a oralidade pode ser caracterizada como origem e berço da cultura popular que, por sua vez, tem sustento, conservação e retorno basicamente na comunicação oral. Por outro, o termo 'oralidade' tem sido utilizado para distinguir sociedades essencialmente orais ou, ainda, para caracterizar as formas de falar que se encontram tanto em culturas que desconhecem como nas que fazem uso da escrita. As expressões oralidade e oralismo, conforme registra Erick Havelock (1995: 17), referem-se também

* Universidade de Brasília - UnB. 
SILVA, Denize Elena Garcia da. A oralidade da linguagem frente à cultura escrita.

a sociedades inteiras que se valem da comunicação oral, dispensando a escrita.

A lectoescritura, por sua vez, envolve não só as questões de leitura e escrita, mas também as práticas sociais de uso da linguagem. Nesse sentido, pode ser associada ao letramento, termo que remete à magnitude da expressão cultura escrita (Havelock, 1995). É oportuno mencionar que a literatura lingüística recente aponta o letramento (literacy) como um fenômeno cultural mais amplo (Barton, 1994), que permite reconhecer a continuidade entre as modalidades oral e escrita da linguagem (Street, 1984; Kleiman, 1995).

\section{Concepções acerca da oralidade}

Discutir a oralidade exige um acercamento inicial às idéias de antropólogos e sociólogos, os quais muito têm registrado sobre suas pesquisas de campo sobretudo em sociedades ágrafas. Cabe mencionar que se trata de estudos que lograram mergulhar na historia das culturas orais antes que a forma verbal fosse plasmada por escrito naquelas sociedades.

Há quarenta anos, aproximadamente, surgiu uma dimensão moderna de considerar-se o discurso oral. Na realidade, tratava-se do enfoque proveniente de incursões novas de investigadores culturais no campo da oralidade, os quais encontraram uma resistência manifesta entre os antigos lingüistas, principalmente quanto à idéia de comparar as modalidades oral e escrita da linguagem. Isto, porque a escrita era concebida apenas como uma espécie de complemento da palavra falada. A esse respeito, a concepção de que a escrita simplesmente representa de forma visivel a língua falada refletia, então, não só a opinião de Saussure, mas também a de E. Sapir, C. Hocket e L. Bloomfield (cf. Ong, 
1987: 25). Ao lado disso, apesar do afã estruturalista e da dedicação no que diz respeito à análise minuciosa e exaustiva da palavra, em seus aspectos de significante e significado, os lingüistas não haviam examinado ainda a fala de uma tradição intensamente oral em contraste com a palavra escrita, produzida obviamente por pessoas com conhecimento das formas de expressão utilizadas na escritura.

Assim é que, entre os anos sessenta e setenta, a oportunidade de conhecer os modos de pensamento e sua expressão verbal, herdados tão somente de uma sociedade prístina oral, motivou o desenvolvimento de estudos comparativos entre culturas orais (sem conhecimento algum da palavra escrita) e culturas com entendimento e uso da escritura. Não obstante, a importância dos contrastes lingüísticos, os quais se evidenciam mediante as diferenças de sociedades distanciadas culturalmente, mais que gerar teorias e fomentar reflexões voltadas para a variedade de aspectos pertinentes à comunicação humana, implicou o aparecimento de uma questão polêmica: a oralidade em oposição à cultura escrita.

As implicações das novas descobertas, ou seja, de uma maneira de expressar verbalmente o pensamento de modo diferente e alheio às formas de expressão de uma sociedade com cultura escrita, deu origem a uma linha de estudos contestável, ainda que muito forte, inspirada em trabalhos procedentes da antropologia social, como os de Jack Goody e Ian Watt (1963) e Goody (1977); da filosofia clássica, como o de Eric Havelock (1963) e de Walter Ong (1977) e, ao mesmo tempo, da psicologia com seu representante David Olson (1977). Surgia, naquela época, a denominada hipótese da "grande divisão", debilitada anos depois justamente pela inclusão da diferença letrados/não-letrados entre os grupos sociais e os individuos. Tal diferença tem constituído, de fato, o reflexo da hipótese da cultura escrita/ oralidade 
SILVA, Denize Elena Garcia da. A oralidade da linguagem frente à cultura escrita.

(orality/literacy) que, em poucas palavras, se apóia na suposição de que a escrita favoreceria a memória verbatim e abstrata e, conseqüentemente, o pensamento lógico, enquanto a memória situacional e concreta estaria associada à tradição oral e ao pensamento "rapsódico" ${ }^{1}$. Desde essa perspectiva, o discurso escrito é caracterizado como descontextualizado e autônomo, enquanto o discurso oral é dependente do contexto ( $c f$. Chafe e Tannen, 1987: 391-2).

Em comparação com outros estudiosos, os antropólogos são os que têm aprofundado e discutido mais diretamente a matéria oralidade em oposição à escrita. Como uma reação crítica contra o modelo dualístico - evidenciado na coexistência do 'primitivo' e 'moderno', do 'mitolỏgico' e 'científico', do 'pré-lógico' e 'lógico' proposto por antropólogos sociais de sua época, Goody (1977) enfoca a escrita, acreditando que sua presença tornaria possivel a distinção entre uma cultura oral e uma cultura letrada, esta caracterizada como moderna e científica em oposição à primeira, considerada primitiva e mitológica. Para o referido antropólogo, a relação entre a palavra e seu referente seria mais geral e abstrata na escrita, sendo esta última menos relativa às especificações de tempo e lugar, quer dizer, menos concreta se comparada às formas da comunicação oral. Com efeito, aqui, o parâmetro da abstração estaria diretamente dependente da escrita. Esta concepção, ainda que pese a fundamentação teórica de Goody, que se baseia não só em Parry, Lord e Havelok, mas também na obra de outros clássicos, conforme lembra Ong (1987: 36), também tem sido alvo de críticas.

É conveniente registrar que, de acordo com Brian Street (1984: 44), a escrita, desde o ponto de vista de Goody, estaria

1 O termo "rapsódico" (do grego rhapsoiden, 'coser um canto'- rhapten, coser; oide canto) é sugerido por Ong $(1977,1982)$, para quem a tradição oral é elaborada basicamente por um tecido ou costura de expressões formulaicas da lingua. Ver também Ong (1987: 22). 
relacionada essencialmente com o pensamento lógico ao fomentar e até mesmo impor seu desenvolvimento; seria responsável pela criação da burocracia e pela transformação de comunidades pequenas em culturas complexas; faria emergir o pensamento científico e as instituições inclusive os processos políticos e democráticos. Nessa perspectiva, a capacidade de abstração, adverte Street de modo contundente, estaria ausente dos grupos iletrados que seriam, portanto, privados do pensamento lógico e científico.

Pode-se sustentar as observações críticas de Street, evocando as palavras de Claude Lévi-Strauss (1976) que, ao referirse a línguas que não possuem termos para expressar conceitos mais genéricos como "árvore" e "animal", afirma com propriedade o seguinte: “...invocando casos em favor de uma suposta inaptidão dos 'primitivos' ao pensamento abstrato, omitiriamos outros exemplos que atestam que a riqueza em palavras abstratas não é só apanágio das línguas civilizadas” (p. 19).

O referido antropólogo estruturalista deixa implícita sua crença de que o pensamento abstrato supera a dicotomia clássica primitivos/civilizados. A propósito, para Lévi-Strauss, o pensamento concreto de grupos não-letrados se distingue do pensamento científico porque, ao usar a natureza como símbolo, aproxima-se da percepção sensorial e estética do mundo. A ciência, ao contrário, procura afastar-se do tipo de conhecimento relacionado diretamente e de modo exclusivo às sensações.

Enquanto os adeptos e mesmo os críticos da hipótese da 'grande divisão' se empenham em investigar a matéria oralidade/cultura escrita em termos de estruturas bipolares, outros estudiosos têm buscado descrever a mudança da oralidade à escritura. Deve-se, aqui, destacar o trabalho posterior de Ong, cujas idéias constituem uma fonte inesgotável de referência para todos aqueles que elegem a interface oralidade/cultura escrita como linha de estudo. 


\section{Oralidade - escrituralidade: uma equação transcendente}

Em seu livro Oralidade e escritura (1982), Ong afirma que é das culturas orais "primárias" que procedem representações verbais de grande valor artístico e humano, o que pode ser ameaçado pela palavra escrita, uma vez que esta se apossa da psique. E nesse sentido, adverte o autor que o conhecimento da escrita, embora seja absolutamente necessário para o desenvolvimento da sociedade, das ciências e para esclarecer a própria língua, constitui um perigo se não é utilizado dentro dos princípios éticos, distantes do rechaço aos antecedentes orais. Por outro lado, observa, ainda, que a oralidade não constitui um ideal e nunca o foi. Além disso, sempre segundo Ong, examinar de maneira positiva a tradição oral não significa defendê-la como um estado permanente para toda cultura. O dominio da palavra escrita, com efeito, abre possibilidades para o enriquecimento do discurso oral e, ao mesmo tempo, para a ampliação do conhecimento e da compreensão desde o ponto de vista sociocultural. Vale a pena registrar a seguinte argumentação do autor:

As culturas orais hoje em dia estimam suas tradições orais e se atormentam pela perda das mesmas, mas nunca encontrei nem tenho ouvido de uma cultura oral que não quisesse alcançar o mais rápido possível o conhecimento da escrita. (...) Do mesmo modo, a oralidade nunca pode eliminar-se por completo: ao lermos um texto o "oralizamos". Tanto a oralidade como o surgimento da escrita a partir da oralidade são necessários para a evolução da consciência.

(Ong, 1987: 169)

Ong enfatiza que o vinculo que se estabelece entre o caminhar da oralidade à escritura não é uma questão de reducionismo mas, sim, de correlação. Os parâmetros propostos pelo autor ser- 
vem como orientação para compreender não só as mudanças sociais e a evolução do pensamento no processo contínuo e solidário do oral ao escrito, mas também para lançar luz ao enfoque da linguagem em termos de sua natureza dialógica e seu caráter interativo. Ong observa, por exemplo, que o falar pressupõe a necessidade de dirigir-se a outro(s). Ainda que em situações de solilóquio, quando alguém fala consigo mesmo, é necessário simular a presença do outro, posto que "o que digo depende da realidade ou fantasia da que creio estar falando, quer dizer, das possiveis reações que posso antecipar" (Ong, op. cit.: p. 170). Nessa perspectiva, o autor comenta que as pessoas, ao formularem qualquer mensagem, já devem ter em mente o outro ou outras pessoas, o que implica reconhecer que a comunicação humana se caracteriza por uma subjetividade reciproca.

Esse procedimento dialógico interior a que se refere Ong parece basear-se não só na presença do outro (interlocutor virtual), mas também nas evocações que se constrói ou que já se tem prontas na mente. Trata-se de evocações que, formuladas como mensagens, podem configurar-se na imaginação como vozes escritas ou como signos falados. ${ }^{2}$ Isso permite conjecturar, ainda, que as motivações cognitivas costumam emergir impregnadas do processo inerente à oralidade, o qual vai ser conjugado ao uníssono com uma espécie de 'escrituralidade' assimilada no interior da mente, esta obviamente conhecedora da escritura.

Cabe, aqui, registrar com referência ao mencionado anteriormente, a seguinte explicação: o campo contínuo entre a oralidade e a escrituralidade é de natureza conceptual, quer dizer, é independente da realização fônica ou gráfica do discurso. Nesse sentido, pode-se conjecturar que, no âmbito dos dominios cognitivos, o aspecto fônico relativo ao oral e o aspecto gráfico perti-

2 As expressões vozes escritas e signos falados foram colhidas no livro de Egbert Baker \& Ahuvia Kahane (eds.): Written voices, spoken signs: tradition, performance, and the epic text. Cambridge, Mass.: Harvard UP (1996). 
SILVA, Denize Elena Garcia da. A oralidade da linguagem frente à cultura escrita.

nente ao escrito coexistem em harmonia, ou seja, não parecem motivar forças internas em competição. Daí a idéia de uma equação transcendente, que decorre justamente dessa natureza conceptual compativel. Quanto ao termo 'escrituralidade', ainda que pese seu caráter de neologismo, considera-se oportuno empregá-lo, principalmente por sua pertinência às conjecturas aqui apresentadas dentro de uma perspectiva lingüístico-discursiva, qual seja, semântica e pragmática ao mesmo tempo.

\section{A fórmula oral de Homero}

O interesse pela compreensão da trajetória da oralidade e suas marcas tem encontrado terreno fértil também entre os estudiosos literários, principalmente a partir da tese de doutorado de Milman Parry (1928) publicada sob o título: $O$ epíteto tradicional em Homero. Enfocando a construção do verso e as formas das palavras nos poemas que conformam a Iliada e a Odisséia, Parry conseguiu demonstrar que Homero usava fórmulas pré-fabricadas, expressões fixas e epítetos que se concentravam em torno dos mesmos temas, os quais também eram apresentados de modo análogo. Conforme registra Ong (1987: 29), estudos posteriores à grande descoberta de Parry permitem destacar, por exemplo, que os epítetos homéricos empregados para o vinho apresentavamse metricamente distintos. Além disso, a eleição de um epiteto não estava diretamente vinculada a seu significado, mas, sim, às necessidades métricas do fragmento de que fazia parte.

Em poucas palavras, a descoberta de Parry fez emergir a base da expressão do poeta mais famoso da herança ocidental, qual seja, os métodos orais de composição. Tal constatação, na época, implicou um princípio paradoxal, uma vez que os letrados haviam aprendido a desconsiderar os textos em que figuravam as frases feitas, as expressões formulaicas, enfim, tudo o 
que envolvia lugar comum, trivialidades. Não obstante, estudos posteriores realizados por Albert Lord (1960) e Havelock (1963), os quais deram continuidade às idéias de Parry, confirmaram definitivamente que os poemas de Homero evidenciam, em sua maioria, fórmulas pré-fabricadas mediante as quais o bardo conseguia armazenar a informação, cumprindo, desse modo, um dos propósitos do poema épico. A esse respeito, Havelock (1991) comenta que a importância da contribuição de Parry repousa no conceito de armazenamento de material na memória oral.

A concepção de Parry pôde ser ampliada e, com base nela, o próprio Havelok conseguiu verificar que os poemas homéricos equivalem a grandes depósitos de informação cultural sobre os costumes, a lei, a propriedade social que também haviam sido registradas. Resulta que, sempre de acordo com Havelock, tanto os mecanismos da memória oral, baseados na repetição e no uso de fórmulas fixas, quanto a função didática da palavra poética enquanto veículo rítmico e depósito de informação, foram paulatinamente substituídos, embora dentro de um espaço de vários séculos, por outras técnicas pertinentes à escrita. Técnicas estas surgidas, obviamente, dentro de um contexto social de letramento ou de cultura escrita.

\section{O letramento e os valores sociais da fala e da escrita}

Na maioria das comunidades letradas, a língua escrita tem uma prioridade social sobre a língua falada em decorrência de seu prestígio e reconhecimento oficial freqüentes. Todavia, podese afirmar que a tradição literária não suplanta a oral. Conforme registra Deborah Tannen (1982b: 3): “quando o letramento é introduzido em uma cultura, há uma sobreposição e entrelaçamento entre as duas modalidades da lingua". Pode-se entender por letramento não só a prática, mas também os eventos relacio- 
SILVA, Denize Elena Garcia da. A oralidade da linguagem frente à cultura escrita.

nados ao uso, função e impacto da escrita na sociedade (Kleiman, 1995). Nessa perspectiva, o letramento perpassa freqüentemente as formas da oralidade no cotidiano.

Com o objetivo de entender porque é atribuida tanta importância ao letramento, Suzzane Romaine (1984) realizou um estudo minucioso, buscando contextos históricos nos quais vários tipos de letramento se desenvolveram. A pesquisadora britânica chegou a um fator relevante, qual seja, o letramento é sempre associado ao poder, embora o uso da lingua para exercê-lo não se restrinja apenas a comunidades letradas. Tal constatação aproxima-se do pensamento de Bourdieu, registrado por Ortiz (1983: 160): “a língua não é somente um instrumento de comunicação ou mesmo de conhecimento, mas instrumento de poder".

Em uma de suas conclusões, Romaine sugere que as chamadas culturas orais e culturas letradas não podem ser explicadas pelas referências às dicotomias cognitivas ou em termos evolucionários simplísticos, mas em termos de organização social. Enfatiza que, em decorrência do avanço da tecnologia da informação e comunicação, convenções do discurso e usos da língua têm crescido, demandando a necessidade de serem aprendidas mediante uma escolarização especial. Além disso, como bem observa a autora: "as sociedades distribuem seus recursos comunicativos de maneira diferente e os indivíduos desenvolvem suas habilidades no contexto das riquezas a que têm acesso" (ibid.: 201). Nessa perspectiva, pode-se inferir que o uso social da língua falada e da lingua escrita guarda relação, de um lado, com o modo pelo qual a transmissão de recursos comunicativos é controlada e, de outro, com a estratificação das classes sociais.

Deve-se lembrar que, mesmo nas sociedades mais desenvolvidas e democrâticas, a escola é efetivamente uma das instituições de controle e distribuição desses recursos comunicativos. Nos países emergentes e com uma cultura de democracia, como 
o Brasil e o México, por exemplo, o sistema educacional ainda se encontra defasado com relação a um aparato teórico-metodológico que possibilite aos alunos desenvolverem suas habilidades orais. E o mais agravante é que a escola, ao ignorar a variedade nãopadrão do repertório lingüístico do aluno, exigindo registros voltados para formas letradas de expressão, muitas vezes perpetua desigualdades e preconceitos sociais, a começar, por exemplo, pelo ensino da lingua materna quando permite que traços da oralidade sejam rejeitados no discurso escrito dos alunos. Isso porque, como enfatiza Magalhães (1991a: 9):

É a lingua escrita que tem prestígio social. Tal prestígio se mostra de forma contundente em nosso sistema educacional e na organização jurídica da sociedade. É a língua escrita, freqüentemente a lingua literária, que se ensina nas escolas. Não existe entre nós uma tradição de estudo da língua oral. Todo o ensino de português, no Brasil, restringe-se ao português escrito. Por outro lado, são as formas escritas que têm peso no direito. Determinadas decisões devem ser tomadas por escrito e assinadas. Pode-se pronunciar um nome próprio de várias maneiras, mas sua grafia nāo pode ser alterada. Dessa forma, a escrita é pública e oficial, enquanto a fala não.

Observa-se, assim, que a lingua escrita mantém o seu prestígio sobre a lingua oral porque representa padrões sociais e culturais que têm na escola um de seus instrumentos de manutenção e, em condições propícias, de reprodução. No entanto, sabese que a superioridade da escrita é puramente funcional, uma vez que decorre de fatores políticos, econômicos e sociais.

Por outro lado, existem duas questões que podem ser relacionadas com as dificuldades que envolvem o processo de ensino/aprendizagem da lingua materna na escola: trata-se da desvalorização das práticas discursivas orais na sala de aula, assim 
SILVA, Denize Elena Garcia da. A oralidade da linguagem frente à cultura escrita.

como da ausência de uma dinâmica pedagógica que permita aos alunos verbalizar sua experiência de vida e exercer, conseqüentemente, seu direito à palavra. Considera-se que dar oportunidade ao aluno de expressar-se oralmente, incentivá-lo a compartilhar dentro da sala de aula sua 'leitura do mundo', como sugeria Paulo Freire (1978), implica abrir caminhos que, em lugar de favorecer a passividade cognitiva, possibilita a ampliação da competência pragmático-discursiva e, o mais importante, o desenvolvimento harmônico da linguagem escrita.

Eis algumas razões pelas quais se aponta também o valor da modalidade oral. Sabe-se que toda lingua se concretiza em uma realização oral e que, além disso, a fala é historicamente anterior à escrita. Mesmo agora, no século XXI, há línguas no mundo que só existem na modalidade oral, embora possam pertencer a comunidades que tenham conhecimento da existência da escrita em outras línguas (Stubbs, 1980: 25-8). Este é o caso da maioria das comunidades indigenas do Brasil.

A modalidade oral é ainda tomada como básica por ser um instrumento social constante na expressão do pensamento e na interação comunicativa. No Brasil, de um ponto vista quantitativo, há o predomínio do oral sobre o escrito. Isso porque a nação passou de uma oralidade baseada no contato pessoal para a oralidade eletrônica dos meios de informação, sem firmar uma tradição de escrita menos formal que a imposta pela norma culta. Além do mais, como discute Basílio (1987), deve-se lembrar que as alternativas de transmissão de mensagem (gravação, banco de dados) e a difusão dos meios de comunicação (rádio, televisão) restringem cada vez mais a utilização da escrita ao necessariamente formal.

Desse modo, embora mantenha o seu valor de prestigio em muitos setores da sociedade, como veículo de informação científica e tecnológica, é fato que a escrita é um código restrito de 
formas e recursos lingüísticos em comparação com a fala (Kress, 1979). Uma prova recente disso é a linguagem dos chats (batepapos) na internet, que se caracteriza como um discurso hibrido por mesclar o estilo oral com o escrito. Os internautas criam, a cada dia, novos usos de recursos gráficos convencionais, e até mesmo símbolos icônicos, numa tentativa de suprir em seus 'bate-papos' os recursos lingüisticos e paralingüísticos próprios da fala.

Os julgamentos feitos com relação à superioridade de uma modalidade sobre a outra decorrem não da funcionalidade, mas dos valores sociais atribuídos a cada uma. Kress (1979) aponta duas razões para a avaliação de superioridade da escrita: o efeito do sistema educacional e o efeito reforçador do sistema social. Quanto à primeira razão, argumenta o lingüista britânico que a escola reforça a superioridade da escrita sobre a fala mediante um 'processo invisivel', ainda que sistemático, decorrente da imposição que pais e professores fazem às crianças quanto ao uso apropriado da língua escrita. O efeito reforçador do sistema social pode ser evidenciado no seguinte exemplo: qualquer indivíduo que deseja identificar-se com um grupo social de prestígio, e mais, que espera ser aceito, adapta seus hábitos lingüísticos ao desse grupo.

Em geral, os estudos comparativos entre a língua oral e a língua escrita ainda enfatizam muito as diferenças em detrimento das similaridades. Esta parece ser também a visão de Mary Kato (1987a: 30), que afirma o seguinte:

...a lingua escrita não pode ser definida como um conjunto de propriedades formais, invariantes e distintas da língua falada. As modalidades oral e escrita da linguagem apresentam uma isomorfia parcial, porque fazem a seleção a partir do mesmo sistema gramatical e podem expressar as mesmas intenções.

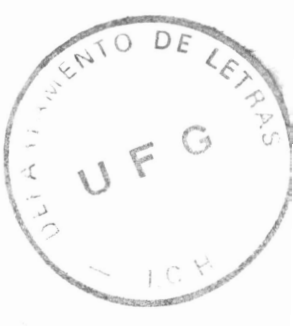


SILVA, Denize Elena Garcia da. A oralidade da linguagem frente à cultura escrita.

De acordo com a referida lingüista, as diferenças entre as duas modalidades vão ser determinadas pelas condições de produção, desde o grau de dependência do contexto situacional (maior na lingua oral que na escrita), passando pelo grau de planejamento responsável pelo nivel de formalidade (do informal ao formal gramaticalizado) até a sujeição da escrita a convenções de ordem prescritiva. Kato sugere que, em se tratando do mesmo gênero - e este é o caso dos dados aqui trabalhados, quais sejam, narrativas orais e escritas em português e em espanhol - a possibilidade de similaridades formais será maior dentro da escala casual/formal, guardadas as possibilidades do grau de tensão estilístico-gramatical para a modalidade escrita.

\section{Conclusão}

Procurou-se discutir a oralidade da linguagem, buscando enfocar as idéias de alguns antropólogos, estudiosos clássicos e lingüistas. Por um lado, não se pode falar de lingua oral sem conhecer, embora de maneira sucinta, a trajetória da mesma na fórmula oral dos versos de Homero. Além disso, escrever sobre a oralidade remete sempre a outras questões como, por exemplo, seu valor em relação à 'escrituralidade', o que permite vislumbrar uma equação transcendente que aponta para a magnitude desses dois conceitos. Por outro lado, é possivel traçar um paralelo entre os valores sociais da fala e da escrita, o que sugere uma ancoragem no letramento.

Dentro do ponto de vista que norteia as reflexões aqui apresentadas, pondera-se que a fala e a escrita constituem dois sistemas discursivos que, apesar dos diferentes valores sociais, complementam-se, sendo este o motivo pelo qual se deve considerá-los como formas de comunicação igualmente importantes. Além do mais, a cada dia que avançam os estudos da linguagem 
dentro de uma perspectiva interacional, torna-se evidente, principalmente nos contextos escolares, a necessidade de se valorizar o desenvolvimento da oralidade para a garantia do amadurecimento na escrita.

\begin{abstract}
This article discusses orality and highlights some of the topic's most relevant issues, mainly when it is dealt with in relation to written language. We start with the conceptions of orality to focus on them within a possible equation in a parallel direction with writing. In search for orality's path, one can draw a line from Homer's formula towards the social values of spoken and written language, associated with literacy.
\end{abstract}

KEYWORDS: orality; written language; social values; literacy.

\title{
Bibliografia
}

BAKER, E. \& KAHANE, A. (eds.) (1996) Written voices, spoken signs: tradition, performance, and the epic text. Cambridge, Mass.: Harvard UP.

BARTON, D. (1994) Talking about literacy. In: Literacy: an introduction to the ecology of written.

Language. London: Blackwell, p. 10-29.

BASÍlIO, M. (1987) Teoria lexical. São Paulo: Ática.

FREIRE, P. (1989) A importância do ato de ler. São Paulo: Cortez.

GOODY, J. e WATT I. (1963) The consequence of literacy. In: GIGLIOLI, P. (ed.) Language and social context. New York: Penguin, p. 311-357. (1977) The domestication of the savage mind. Cambridge: Cambridge University Press.

CHAFE, W. e TANNEN, D. (1987) The relation between written and spoken language. Em Annual Rev. Antropology, 16: 383-407.

HAVELOCK, E. (1963) Preface to Plato. Cambridge, Mass.: Harvard University Press. 
SILVA, Denize Elena Garcia da. A oralidade da linguagem frente à cultura escrita.

(1991) La equación oral-escrito: una fórmula para la mentalidad moderna. In: OLSON, D. e TORRANCE, N. (orgs.) Cultura escrita y oralidad, ed. cast. (1995) Trad. G. Vitale. Barcelona: Gedisa, p. 25-46.

KATO, M. (1987a) No mundo da escrita: uma perspectiva psicolingüística. São Paulo: Ática.

KLEIMAN. A. (1995) Introdução: O que é letramento. In: KLEIMAN, A. (org.) Os significados do letramento. Campinas, SP: Mercado de Letras, p. 15-61.

KRESS, G. (1979) The social values of speech and writing. In: FOWLER, R. et alii (eds.) Language and control. London: Routledge \& Kegan Paul, p. 46-62.

LEVI-STRAUSS, C. (1976) O pensamento selvagem. $2^{\text {a }}$ ed. Trad. M. Celeste S. e A. Aguiar. São Paulo: Companhia Ed. Nacional (1962).

LORD, A. (1960) The singer of tales. Harvard Studies in Comparative Literature, 24. Cambridge,-Mass.: Harvard University Press.

MAGALHÃES, I. (1991a) Língua oral, língua escrita: uma questão de valores sociais. In: Pré-textos (2). UnB: NELI.

OLSON, D. (1977) From utterance to text: The bias of language in speech and writing. In: Harvard Educational Review, 47 (3).

ONG, W. (1977) Interface of the word. Ithaca, New York: Cornell University Press.

. (1982) Orality and literacy: The technologizing of the word [Oralidade y escritura: tecnologias de la palabra, versão cast. (1987) Trad. A. Scherp]. México: Fondo de Cultura.

ORTIZ, R. (org.). (1983) Pierre Bordieu: Sociologia. Trad. P. Monteiro e A. Auzmendi. São Paulo: Ática.

PARRY, M. (1971) The collected papers of Milman Parry (A. Parry, comp.). Oxford: Oxford University Press (Clarendon Press).

ROMAINE, S. (1984) The language of children and adolescents. New York : Basil Blackwell.

STREET, B. (1984) Literacy in theory and practice. Cambridge: Cambridge University Press.

STUBBS, M. (1980) Language and literacy: the sociolinguistics of reading and writing. London: Routledge e Kegan Paul. 
Rev. ANPOLL, n. 9, p. 23-39, jul./dez. 2000

TANNEN, D. (1982b) The oral/literate continuum in dsicourse. In: TANNEN, D. (ed.) Spoken and written language: exploring orality and literacy. Advances in Discourse Processes, vol. IX. Norwood, New Jersey: Ablex, p. 1-16.

. (1987) Repetition in conversation as spontaneous formulaicity. In: JOHNSTONE, B. (ed.) TEXT 7(3), p. 215-243. 